EXTENDED REPORT

\title{
Proteolysis of serum amyloid $A$ and $A A$ amyloid proteins by cysteine proteases: cathepsin B generates AA amyloid proteins and cathepsin $L$ may prevent their formation
}

\author{
C Röcken, R Menard, F Bühling, S Vöckler, J Raynes, B Stix, S Krüger, A Roessner, T Kähne
}

Ann Rheum Dis 2005;64:808-815. doi: 10.1136/ard.2004.030429

See end of article for
authors' affiliations
$\ldots \ldots \ldots \ldots \ldots \ldots \ldots \ldots$
Correspondence to:
Dr C Röcken, Institute of
Pathology, OOtto-von-
Guericke-University,
Leipziger Str 44, D-39120
Magdeburg, Germany;
christoph.roecken@
medizin.uni-magdeburg.
de
Accepted
9 November 2004

\begin{abstract}
Background: AA amyloidosis develops in patients with chronic inflammatory diseases. The AA amyloid proteins are proteolytic fragments obtained from serum amyloid A (SAA). Previous studies have provided evidence that endosomes or lysosomes might be involved in the processing of SAA, and contribute to the pathology of AA amyloidosis.

Objective: To investigate the anatomical distribution of cathepsin (Cath) B and CathL in AA amyloidosis and their ability to process SAA and AA amyloid proteins.

Methods and results: CathB and CathL were found immunohistochemically in every patient with AA amyloidosis and displayed a spatial relationship with amyloid in all the cases studied. Both degraded SAA and $\mathrm{AA}$ amyloid proteins in vitro. With the help of mass spectrometry 27 fragments were identified after incubation of SAA with CathB, nine of which resembled AA amyloid proteins, and seven fragments after incubation with CathL. CathL did not generate AA amyloid-like peptides. When native human AA amyloid proteins were used as a substrate 26 fragments were identified after incubation with CathB and 18 after incubation with CathL.

Conclusion: The two most abundant and ubiquitously expressed lysosomal proteases can cleave SAA and AA amyloid proteins. CathB generates nine AA amyloid-like proteins by its carboxypeptidase activity, whereas CathL may prevent the formation of AA amyloid proteins by endoproteolytic activity within the $\mathrm{N}$ terminal region of SAA. This is particularly interesting, because AA amyloidosis is a systemic disease affecting many organs and tissue types, almost all of which express CathB and CathL.
\end{abstract}

$\mathrm{S}$ econdary systemic AA amyloidosis develops in patients with chronic or recurrent inflammatory diseases, such as rheumatoid arthritis. ${ }^{1}$ The AA amyloid protein is derived from serum amyloid A (SAA) and lacks one or two amino acids at the $\mathrm{N}$-terminus, and between 15 and 83 amino acids at the C-terminus (fig 1). Only a small proportion of the amyloid deposits enclose intact SAA. Most of the AA amyloid proteins have undergone proteolysis. Evidence is accumulating that AA amyloidosis is associated with, or caused by, defective SAA degradation. ${ }^{2}{ }^{3}$ As yet, little is known about the putative proteases and compartments, which may contribute to the formation of AA amyloid proteins.

In a previous study we demonstrated that matrix metalloproteinases (MMPs) can cleave SAA and AA amyloid proteins. ${ }^{4}$ MMPs have their optimum $\mathrm{pH}$ at neutral or near neutral $\mathrm{pH}$ and may cleave SAA and AA amyloid proteins in a pericellular or extracellular compartment. Cleavage may also occur intracellularly in macrophages, probably in an endosomal or lysosomal compartment. ${ }^{5}$ Macrophages are commonly found adjacent to amyloid deposits ${ }^{6}$ and can bind and internalise SAA, forming amyloid deposits in vitro. They synthesise a broad range of proteases, which may process the precursor protein, and may also play a part in the degradation of amyloid deposits. ${ }^{6}$

The endosomal and lysosomal compartments are particularly rich in cathepsin (Cath) B and CathL. They are active at acidic to neutral $\mathrm{pH}$ and have broad substrate specificity. ${ }^{78}$ Owing to their ubiquitous expression and an ever increasing number of known substrates, the physiological functions of CathB and CathL have been linked to a multitude of metabolic processes. ${ }^{8}$ They are also expressed in all phenotypically diverse macrophages, ${ }^{9}$ which raises the question of whether CathB and CathL can degrade SAA and AA amyloid proteins, and indicates a possible involvement in AA amyloidogenesis.

In this study we investigated the anatomical distribution of CathB and CathL in human AA amyloidosis and their proteolytic action on SAA and AA amyloid proteins.

\section{PATIENTS AND METHODS}

\section{Patient selection}

Twenty eight archived, formalin fixed, paraffin embedded, necropsy specimens from 10 patients (seven men, three women; mean age 56.7 years (range 35-70)) were used in this study. These patients have been described previously, when histological examination demonstrated the presence of generalised AA amyloidosis. ${ }^{10}{ }^{11}$ The classification of amyloid was based on immunohistochemistry and clinical history. ${ }^{10}{ }^{11}$ The following organ specimens were available for use in this study: liver (from 10 patients), spleen (10 patients), and kidney (8 patients). Variable amounts of amyloid were present in all the specimens as vascular and interstitial deposits.

\section{Preparation of AA amyloid proteins}

Unfixed splenic tissue containing amyloid was available from one of the above patients with generalised AA amyloidosis. About $6 \mathrm{~g}$ of amyloidotic tissue was used to prepare amyloid proteins by the water wash procedure. ${ }^{6}$ Delipidated samples were then dissolved in sample buffer containing $6 \mathrm{M}$ guanidine $\mathrm{HCl}, 0.1 \mathrm{M}$ Tris- $\mathrm{HCl}(\mathrm{pH} 8.0), 0.2 \%$ ethylenediaminetetraacetic acid, and $0.1 \mathrm{M}$ dithiothreitol,

Abbreviations: Cath, cathepsin; HS, heparan sulphate; MALDI-TOFMS, matrix assisted laser desorption/ionisation time of flight mass spectrometer; MMPs, matrix metalloproteinases; rSAA, recombinant serum amyloid $A$; SAA, serum amyloid $A$ 
No. Reference

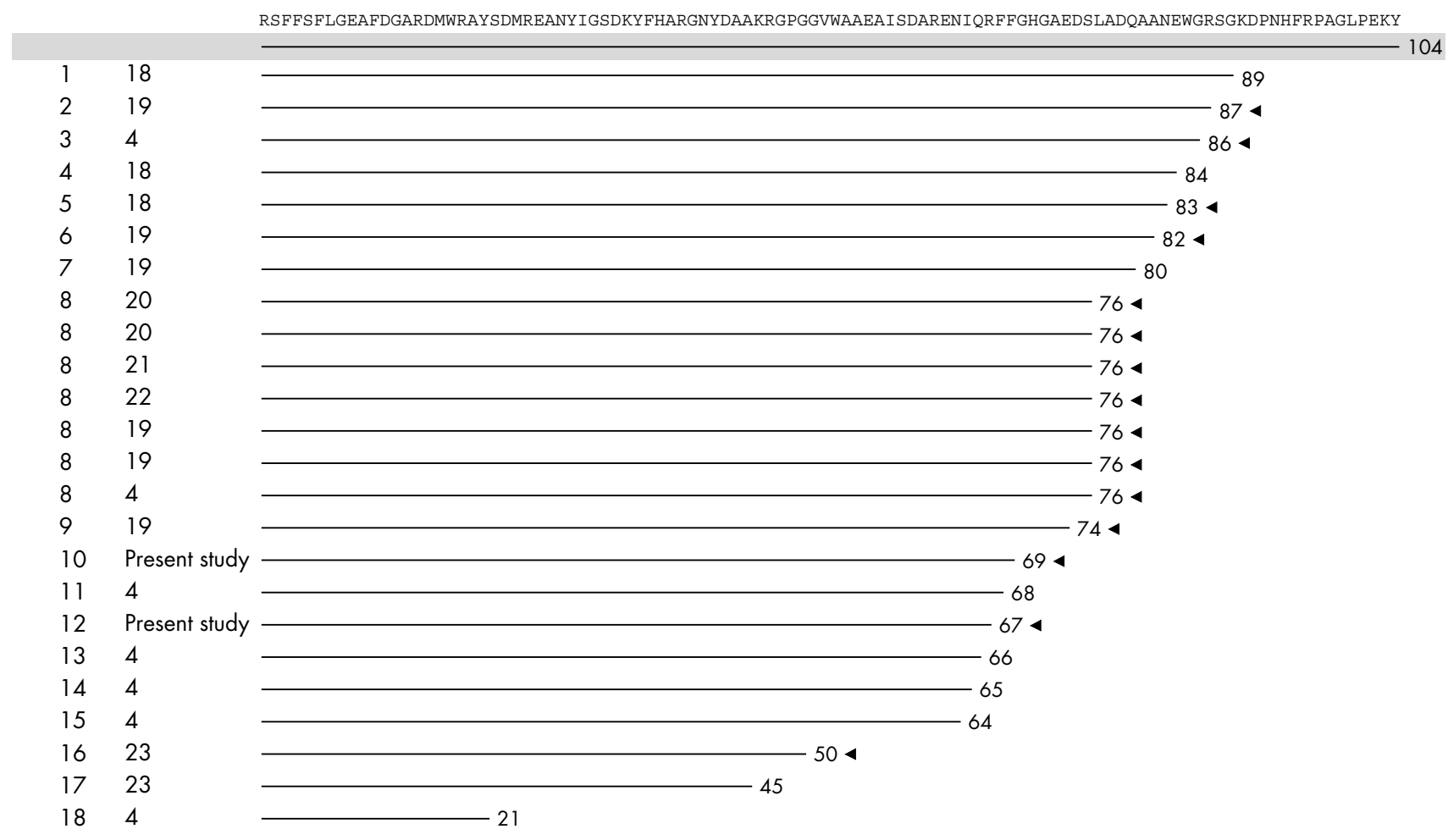

4 indicates the human AA amyloid protein, which resembles a peptide generated in vitro by CathB (current study)

Figure 1 AA amyloid proteins that have been characterised to date. The fibril protein only lacks one or two amino acids at the $\mathrm{N}$-terminus, and between 15 and 83 amino acids at the C-terminus.

and separated by gel filtration with Sepharose CL-6B (SigmaAldrich, Deisenhofen, Germany). The column was equilibrated and eluted with $8 \mathrm{M}$ urea in $0.01 \mathrm{M}$ sodium citrate$\mathrm{HCl}$ buffer ( $\mathrm{pH}$ 3.0). Pooled fractions of the elution peak were dialysed against distilled water, concentrated, and dissolved in guanidine $\mathrm{HCl}$. The AA amyloid proteins were finally purified by high pressure liquid chromatography and a Jupiter 5u C5 300 A column $(250 \times 4.60 \mathrm{~mm}$; Phenomenex, Aschaffenburg, Germany). The eluent consisted of an aqueous $95 \%$ acetonitrile- $0.085 \%$ trifluoroacetate solution. Peaks containing purified AA amyloid proteins were identified by sodium dodecyl sulphate-polyacrylamide gel electrophoresis, ${ }^{11}$ western blotting, ${ }^{11}$ and mass spectrometry.

\section{Production of human CathB and CathL}

The recombinant human CathB and CathL were produced and purified as described elsewhere. ${ }^{12}$ The specific activity against the standard Cbz-FR-MCA substrate as expressed by the $\mathrm{k}_{\mathrm{cat}} / \mathrm{K}_{\mathrm{M}}$ value at $\mathrm{pH} 6.0$ was $4.25 \times 10^{5} \mathrm{M}^{-1} \mathrm{~s}^{-1}$ for CathB and $5.0 \times 10^{7} \mathrm{M}^{-1} \mathrm{~s}^{-1}$ for CathL.

\section{Degradation experiments}

In vitro degradation experiments were performed as follows: recombinant SAA (rSAA; Peprotech, London, UK) or AA amyloid proteins were dissolved in water to a concentration of $4 \mathrm{mg} / \mathrm{ml}$ and mixed in a ratio of $1: 1$ with reaction buffer (200 mM sodium acetate, $10 \mathrm{mM}$ EDTA, and $5 \mathrm{mM}$ dithiothreitol). Acetic acid was used to adjust to pH 5.2. Degradation was performed at $37^{\circ} \mathrm{C}$ and was started by the addition of CathB $(0.1,0.4$, and $1.7 \mu \mathrm{mol} / \mathrm{l})$ or CathL $(3,10$, and $40 \mathrm{nmol} / \mathrm{l}$ ). The reaction was stopped by the addition of the cysteine protease inhibitor E64 (1.6 mmol/l; Bachem,
Heidelberg, Germany). Omission of cathepsins and incubation in the presence of E64 $(200 \mu \mathrm{mol} / \mathrm{l})$ served as a control.

\section{Mass spectrometry}

Cleavage sites were determined with a matrix assisted laser desorption/ionisation time of flight mass spectrometer (MALDI-TOF-MS). Human rSAA or AA amyloid proteins were incubated with either CathB or CathL as described above, and $0.5 \mu \mathrm{l}$ aliquots were removed at the times indicated in figs 2 and 4 . The samples were subsequently co-crystallised with $0.5 \mu \mathrm{l}$ sinapinic acid $(20 \mathrm{mg} / \mathrm{ml})$ in $70 \%$ acetonitrile on a SCOUT 384 MALDI target. The mass spectrometry was performed on a MALDI-TOF-MS (Reflex III; Bruker Daltonics, Germany) in linear mode with internal calibration. The BioTools 2.0 software (Bruker Daltonics, Germany) was used for the annotation of the SAA fragments; the accepted mass tolerance was $100 \mathrm{ppm}$.

\section{Immunohistochemistry}

Immunostaining was performed as described previously ${ }^{13}$ using monoclonal antibodies directed against CathB (dilution 1:50) and CathL (1:15; both Calbiochem, Darmstadt, Germany). Primary antibodies were omitted or replaced by preimmune serum for negative controls.

\section{RESULTS}

Degradation of rSAA by CathB and CathL

The first set of experiments aimed at investigating whether CathB and CathL can degrade SAA and whether the generated fragments resemble AA amyloid proteins found in vivo. The optimum experimental conditions at which CathB and CathL cleave rSAA were found in preliminary 
A
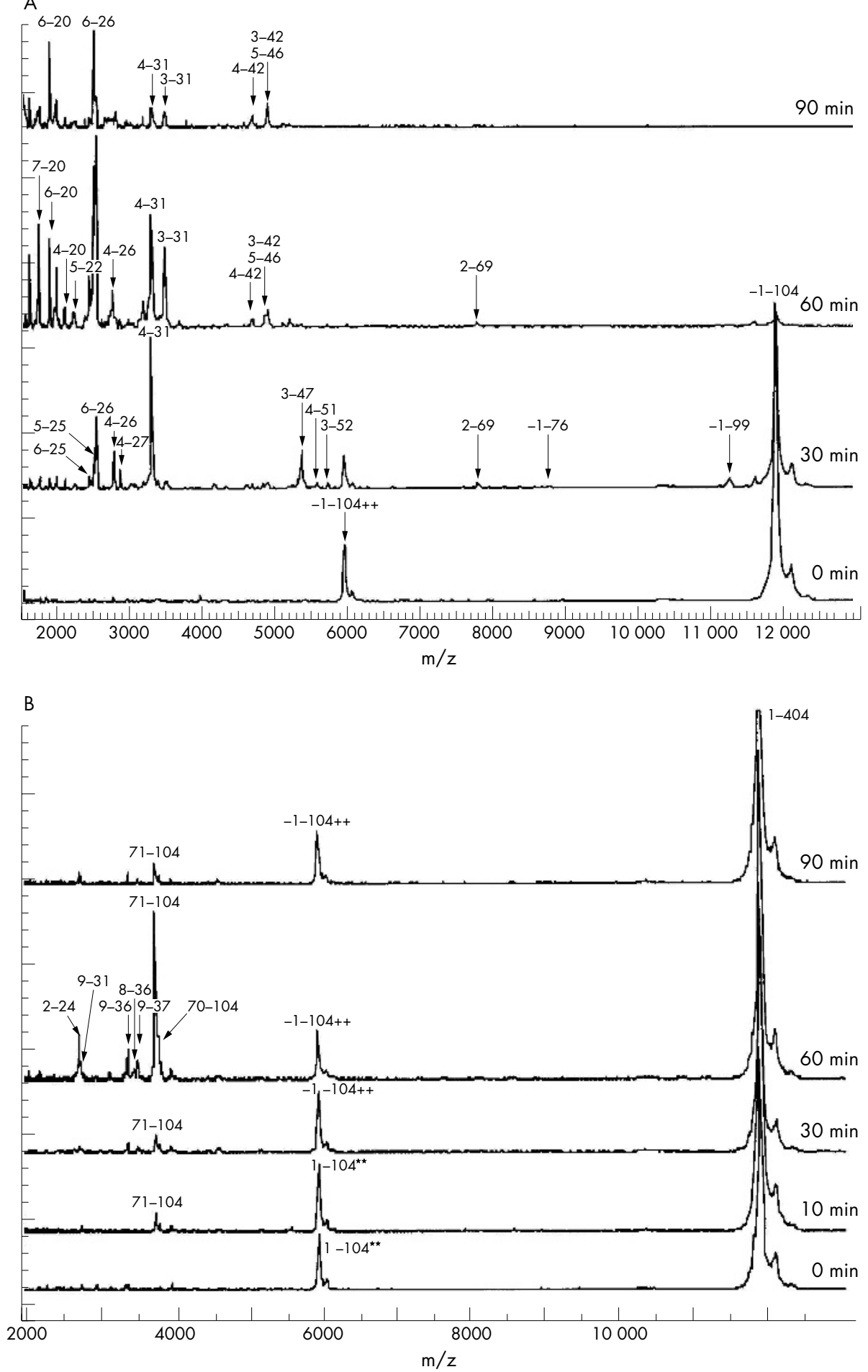

Figure 2 In vitro degradation experiments using rSAA as substrate were analysed by mass spectrometry and showed that each protease has its own proteolytic profile. In vitro degradation was performed at $\mathrm{pH} 5.2$ for the indicated times at $37^{\circ} \mathrm{C}$. Incubation without cysteine proteases served as a control (0 min). rSAA $(0.5 \mathrm{mg} / \mathrm{ml})$ was incubated with $(A)$ CathB $(1.7 \mu \mathrm{mol} / \mathrm{I})$ and (B) CathL $(40 \mathrm{nmol} / \mathrm{l})$. experiments (data not shown). Several protease concentrations were chosen, at which rSAA $(0.5 \mathrm{mg} / \mathrm{ml})$ is cleaved stepwise after addition of active protease. Degradation was assessed by mass spectrometry.

Figure 2A shows mass spectra obtained after incubation of rSAA with CathB. CathB degrades rSAA completely at a concentration of $1.7 \mu \mathrm{mol} / \mathrm{l}$ and less efficiently at concentrations below $0.4 \mu \mathrm{mol} / \mathrm{l}$. However, the cleavage products were identical, irrespective of the concentration of CathB. Analysis of the degradation profile over time showed that CathB has mainly carboxypeptidase, some endoproteolytic, and minor aminopeptidase activity. The cleavage sites between residues $\mathrm{Gly}^{31}-\mathrm{Ser}^{32}$, and $\mathrm{Val}^{52}-\mathrm{Trp}^{53}$ were found at low protease concentrations and no intermediates were detectable, suggesting endoproteolytic activity at these sites. Using different concentrations of CathB, we identified fragments ending at residues Gly ${ }^{99}, \operatorname{Arg}^{87}, \mathrm{Gly}^{86}, \operatorname{Trp}^{85}, \mathrm{Asn}^{83}, \mathrm{Ala}^{82}, \mathrm{Ala}^{78}, \mathrm{Ser}^{76}$, $\mathrm{Glu}^{74}, \mathrm{Phe}^{69}, \operatorname{Arg}^{67}, \mathrm{Gly}^{50}, \mathrm{Lys}^{46}, \mathrm{Tyr}^{42}, \mathrm{Ala}^{27}, \mathrm{Glu}^{26}, \mathrm{Arg}^{25}$, $\mathrm{Ser}^{22}$, and $\mathrm{Ala}^{20}$, which are probably related to carboxypeptidase activity, while the fragment spanning residues Phe $^{3}$ to $\mathrm{Arg}^{47}$ may be generated from the $\mathrm{Phe}^{3}$ to $\mathrm{Val}^{52}$ fragment by carboxypeptidase activity or may be an alternative 
A

-1 MRSFFSFLGEAFDGARDMWRAYSDMREANYIGSDKYFHARGNYDAAKRGPGGVWAAEAISNARENIQRFFGRGAEDSLADQAANEWGRSGKDPNHFRPAGLPEKY 104
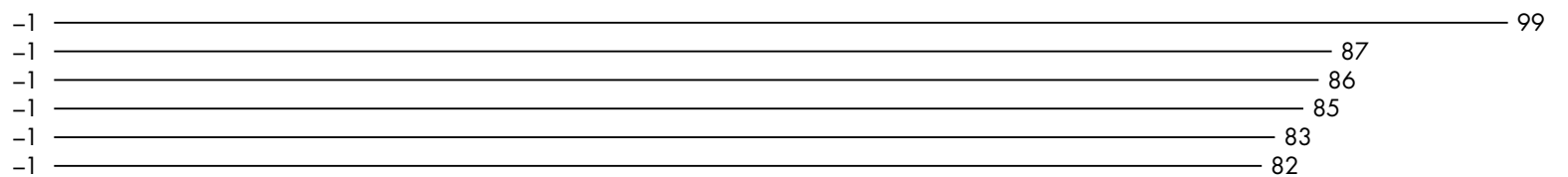

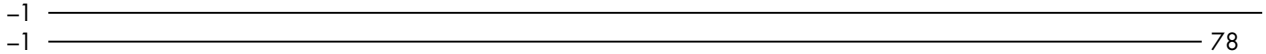
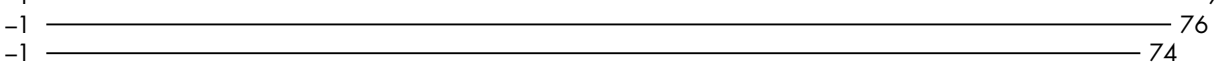

$-12-69$

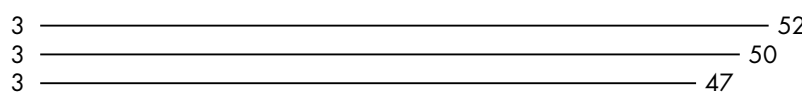

$3 \longdiv { 5 \longrightarrow 4 2 } 4 6$

$4 \longrightarrow 42$

$3 \longrightarrow 31$

$4 \longrightarrow 27$

$4 \longdiv { 2 0 } 2 7$

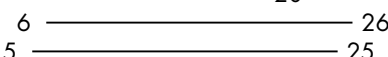

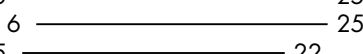

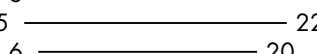

$7 \longrightarrow 20$

B

-1 MRSFFSFLGEAFDGARDMWRAYSDMREANYIGSDKYFHARGNYDAAKRGPGGVWAAEAISNARENIQRFFGRGAEDSLADQAANEWGRSGKDPNHFRPAGLPEKY 104
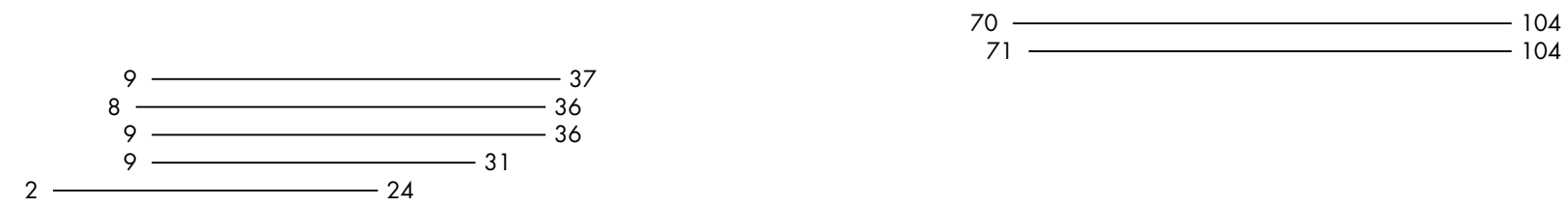

Figure 3 Cleavage products obtained by the incubation of rSAA with (A) CathB and (B) CathL.

endoproteolytic cleavage product. CathB also cleaved the Nterminal end of SAA between residue $\mathrm{Ser}^{2}-\mathrm{Phe}^{3}, \mathrm{Phe}^{3}-\mathrm{Phe}^{4}$, $\mathrm{Phe}^{4}-\mathrm{Ser}^{5}, \mathrm{Ser}^{5}-\mathrm{Phe}^{6}$, and $\mathrm{Phe}^{6}-\mathrm{Leu}^{7}$, indicating minor aminopeptidase activity. No degradation was seen in the absence of active protease or in the presence of E64.

The degradation profile of CathL (fig 2B) differed completely from that of CathB (fig 2A). Only endoprotease activity could be found. Irrespective of the concentration used $(3,10$, and $40 \mathrm{nmol} / \mathrm{l})$, we identified only seven fragments. The following cleavage sites were annotated: between $\mathrm{Arg}^{1}$ $\mathrm{Ser}^{2}, \mathrm{Leu}^{7}-\mathrm{Gly}^{8}, \mathrm{Gly}^{8}-\mathrm{Glu}^{9}, \mathrm{Met}^{24}-\mathrm{Arg}^{25}, \mathrm{Gly}^{31}-\mathrm{Ser}^{32}, \mathrm{Phe}^{36}-$ $\mathrm{His}^{37}, \mathrm{His}^{37}-\mathrm{Ala}^{38}, \mathrm{Phe}^{69}-\mathrm{Gly}^{70}$, and Gly ${ }^{70}-\mathrm{Arg}^{71}$ (fig 2B). No further fragments could be identified, suggesting that the intermediates are rapidly degraded by CathL. Again, no degradation was seen in the absence of active protease or in the presence of E64.

The fragments, here identified by mass spectrometry, were compared with AA amyloid proteins purified from human amyloidotic tissue. This showed that CathB can generate peptide fragments resembling AA amyloid proteins (see fig l). In contrast, CathL did not create a single fragment resembling an AA amyloid protein.

\section{Degradation of native human AA amyloid proteins by CathB and CathL}

We next investigated degradation of native human AA amyloid proteins. After the extraction of AA amyloid proteins by the water wash procedure, gel filtration, and purification by high pressure liquid chromatography, we finally obtained a protein mixture of five AA amyloid proteins spanning residues $\mathrm{Ser}^{2}$ to $\mathrm{Asn}^{64}, \mathrm{Ser}^{2}$ to $\mathrm{Ile}^{65}, \mathrm{Ser}^{2}$ to $\mathrm{Gln}^{66}, \mathrm{Ser}^{2}$ to $\mathrm{Arg}^{67}$, and $\mathrm{Phe}^{3}$ to $\mathrm{Phe}^{69}$ (figs 4 and 5). Both CathB and CathL could completely degrade these native AA amyloid proteins. Degradation by CathB showed primarily carboxypeptidase activity and some aminopeptidase activity (fig 4A), whereas CathL showed mainly endoproteolytic activity (fig 4B). No degradation was seen in the absence of active protease or in the presence of E64. Figures 3 and 5 list all the fragments obtained after degradation with CathB and CathL.

\section{Prevalence of CathB and CathL in human AA amyloidosis}

The in vitro experiments provide strong evidence that CathB and CathL can degrade SAA and AA amyloid proteins and may be involved in the pathology of AA amyloid. To provide further evidence for a putative role of CathB and CathL in AA amyloidosis, we studied their spatial distribution in patients who had had AA amyloidosis. Twenty eight archived, formalin fixed, paraffin embedded, necropsy specimens from 10 patients were studied.

CathB and CathL were found immunohistochemically in every patient (100\%) with AA amyloidosis (fig 6) and displayed a spatial relationship with amyloid in all the cases studied. Intracellular immunostaining was confined mainly to macrophages, multinucleated giant cells, myocytes of vessel walls, and endothelial cells, which were either attached to, or enclosed by, amyloid deposits. CathB and CathL immunoreactive multinucleated giant cells (fig 6), respectively, spatially related to amyloid, were found in the spleen (five patients), liver (four), and kidney (three). 


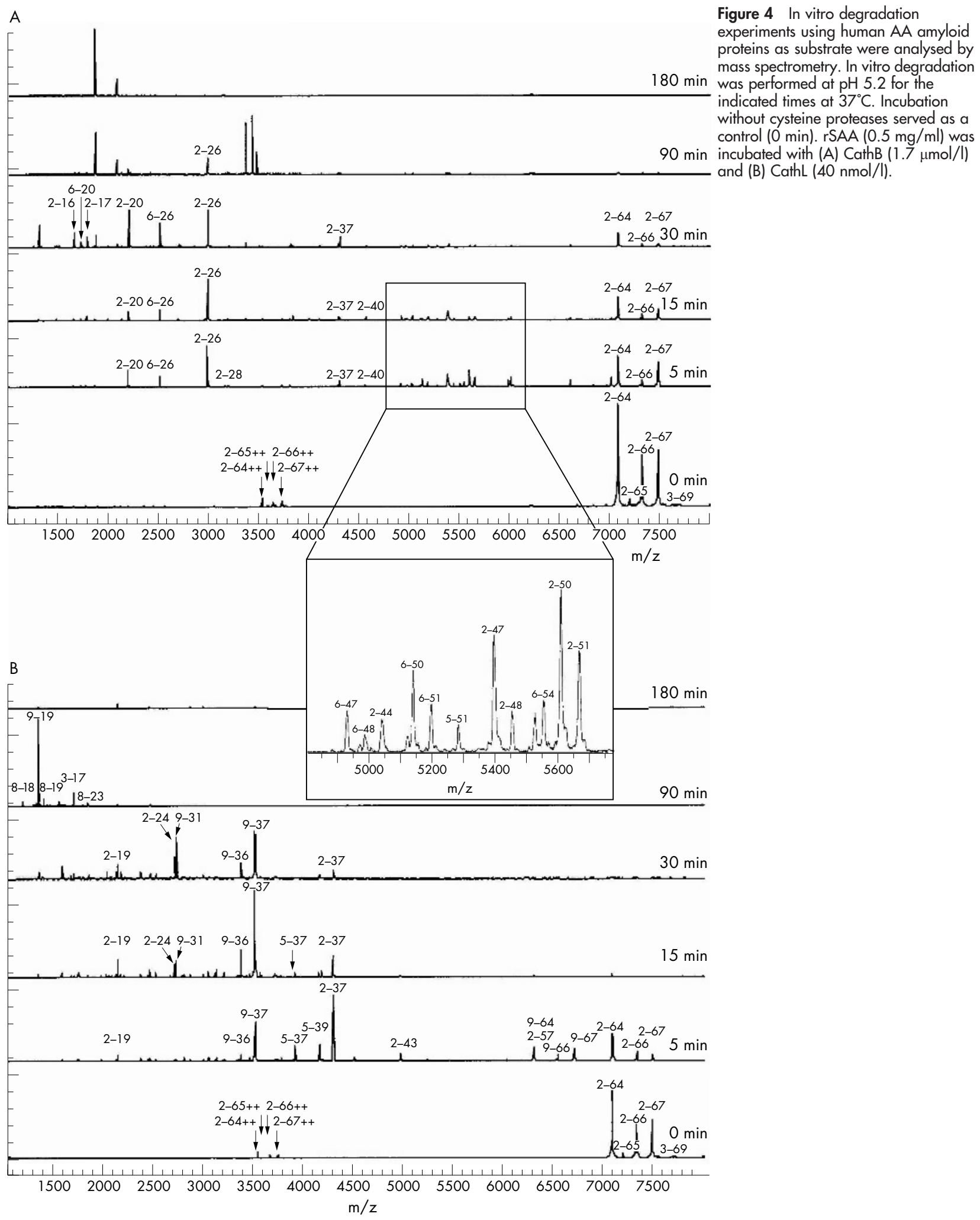

Only CathB was found extracellularly within the amyloid deposits of eight $(80 \%)$ patients, confined to the spleen (six patients), liver (four), and kidney (two).

No immunostaining was seen after incubation with preimmune serum (fig 6) or after the omission of the primary antibody.

\section{DISCUSSION}

In human AA amyloidosis, all amyloid proteins characterised so far are fragments of a larger precursor protein and are the result of proteolysis (fig 1). Previous studies identified different proteases which might cleave SAA. These include CathG, neutral serine esterase, CathD, elastase, CathB, and 
3 FFSFLGEAFDGARDMWRAYSDMREANYIGSDKYFHARGNYDAAKRGPGGVWAAEAISDARENIQRFF 69 protein with (A) CathB and (B) CathL.

2 SFFSFLGEAFDGARDMWRAYSDMREANYIGSDKYFHARGNYDAAKRGPGGVWAAEAISDARENIQR 67

2 SFFSFLGEAFDGARDMWRAYSDMREANYIGSDKYFHARGNYDAAKRGPGGVWAAEAISDARENIQ 66

2 SFFSFLGEAFDGARDMWRAYSDMREANY IGSDKYFHARGNYDAAKRGPGGVWAAEAISDARENI 65

2 SFFSFLGEAFDGARDMWRAYSDMREANYIGSDKYFHARGNYDAAKRGPGGVWAAEAISDAREN 64

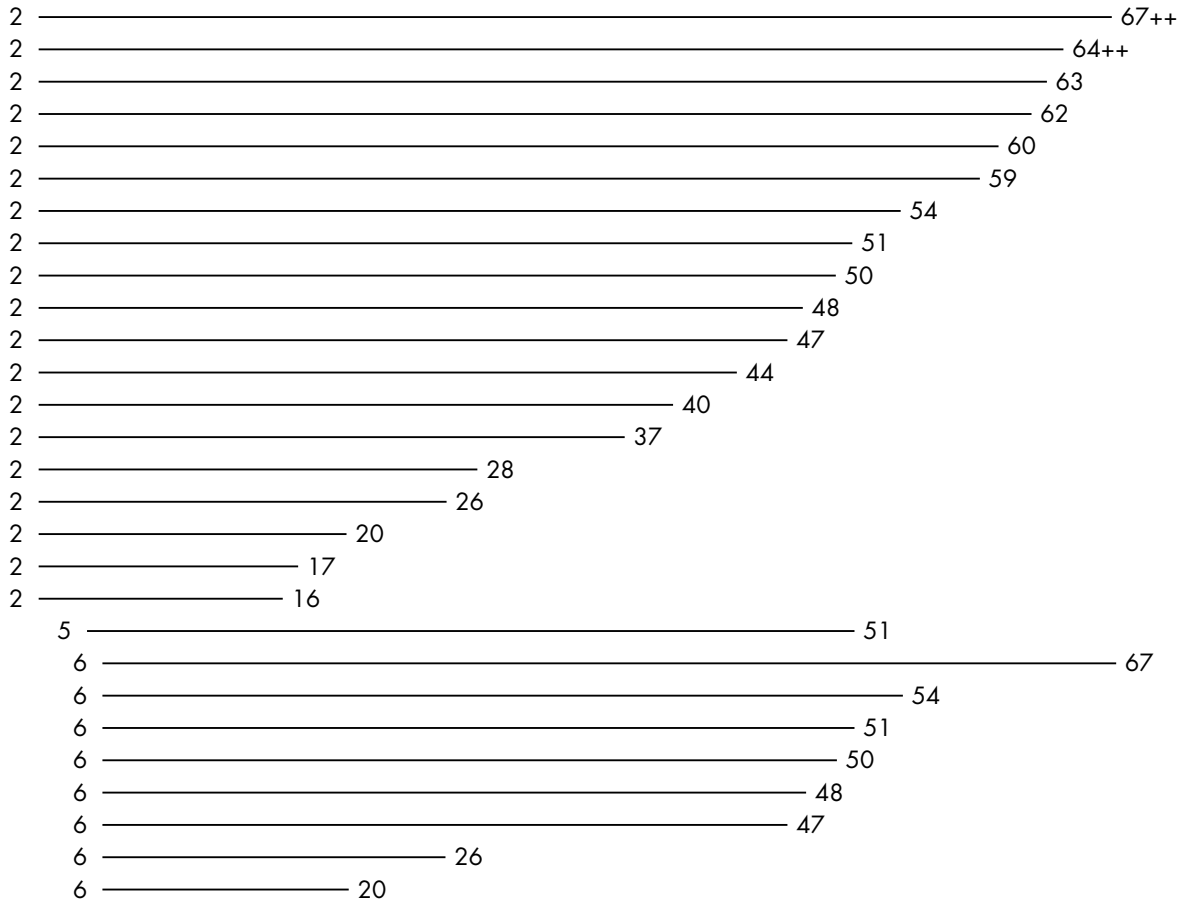

B

3 FFSFLGEAFDGARDMWRAYSDMREANY IGSDKYFHARGNYDAAKRGPGGVWAAEAISDARENIQRFF 69

2 SFFSFLGEAFDGARDMWRAYSDMREANY IGSDKYFHARGNYDAAKRGPGGVWAAEAISDARENIQR 67

2 SFFSFLGEAFDGARDMWRAYSDMREANYIGSDKYFHARGNYDAAKRGPGGVWAAEAISDARENIQ 66

2 SFFSFLGEAFDGARDMWRAYSDMREANYIGSDKYFHARGNYDAAKRGPGGVWAAEAISDARENI 65

2 SFFSFLGEAFDGARDMWRAYSDMREANYIGSDKYFHARGNYDAAKRGPGGVWAAEAISDAREN 64
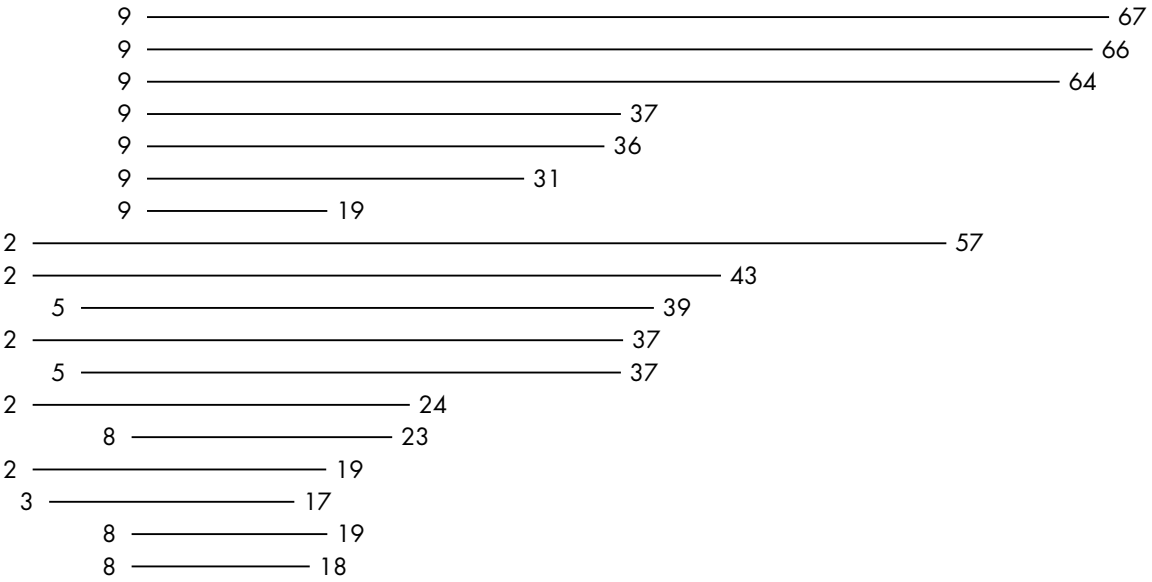

MMPs (for a review see Röcken and Shakespeare ${ }^{1}$ ). Elastase and CathD cleave SAA mainly within its $\mathrm{N}$-terminal half (table 1) and do not generate AA amyloid proteins. Studies using synthetic peptides have shown that the first 10 to 15 amino acids of the molecule are the most important in the formation of amyloid. ${ }^{1}$ All AA amyloid proteins analysed to date have an almost intact $\mathrm{N}$-terminus, which lacks no more than one or two amino acids, substantiating reports that degradation of SAA further along the $\mathrm{N}$-terminus by CathD may prevent the formation of amyloid. ${ }^{1}$

MMPs show endoproteolytic activity on SAA and AA amyloid proteins at different sites of the molecules (table 1). They generate several fragments with intact $\mathrm{N}$-termini, ${ }^{4}$ ending between positions $\mathrm{Gly}^{51}$ and $\mathrm{Ala}^{57}$, none of which have been found in human AA amyloid deposits until now (fig 1, table 1). Finally, a single study used CathB and 


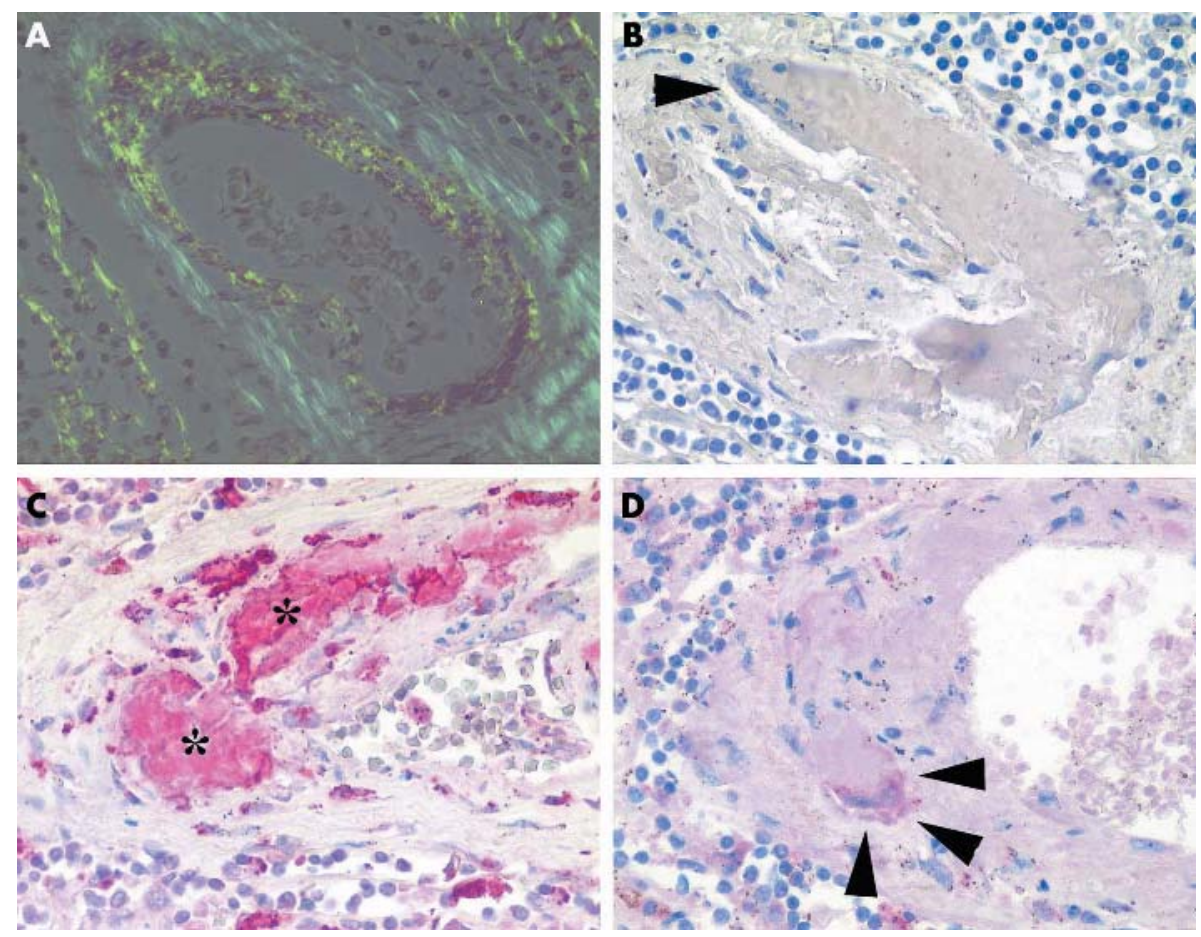

Figure 6 Splenic specimens from a patient with generalised AA amyloidosis. (A) Green birefringent vascular amyloid deposits were found in Congo red stained specimens. (B) No immunostaining was found after incubation with preimmune serum. (C, D) CathB and CathL were found in cells lining amyloid deposits. Note the immunostaining of the amyloid deposits with anti-CathB antibody (asterisk). Occasionally, multinucleated histiocytic giant cells were found lining amyloid deposits (arrow heads), which also expressed cysteine proteases (D). Congo red staining in polarised light; immunostaining with preimmune serum, anti-CathB, and anti-CathL; haematoxylin counterstain. Original magnification $\times 400$.

identified a cleavage site between positions $\mathrm{Ser}^{76}$ and $\mathrm{Leu}^{77}$, generating a peptide identical to AA amyloid protein spanning residues $\mathrm{Arg}^{1}$ to $\mathrm{Ser}^{76}$, which, so far, has been most commonly found in AA amyloid (fig 1 ). ${ }^{14}$ As yet no one type of protease has been identified, which can generate the diverse AA amyloid proteins found in human tissue. Figure 1 lists all these human AA amyloid proteins currently characterised, which often differ from each other by only one or two amino acids. In further support of this notion, we have characterised AA amyloid proteins in two patients using mass spectrometry. ${ }^{4}$ Previously, we found eight different AA amyloid proteins ${ }^{4}$ and in this study five different AA amyloid proteins (see fig 1). In both cases, the AA amyloid proteins often differed only by a single amino acid. After incubation of rSAA with CathB in vitro, we were able to create fragments, of which nine resembled AA amyloid proteins. In keeping with the predominant carboxypeptidase activity of CathB, the cleavage products differed only by one or two amino acids. CathB might be a putative candidate responsible for the generation of most of the different AA amyloid proteins found in humans, as all these observations strongly suggest that AA amyloid proteins might be created by a carboxypeptidase with relatively low sequence specificity, such as CathB.

The proteolytic profile of CathL contrasted strongly with that of CathB, showing predominantly endoproteolytic activity. In six cleavage sites (see figs $3 \mathrm{~B}$ and $5 \mathrm{~B}$ ), Phe was found at position $\mathrm{P} 1, \mathrm{P} 2$, or $\mathrm{P} 3$, which is in keeping with the expected cleavage sites of CathL. ${ }^{7}$ CathL generated no fragments resembling AA amyloid proteins.

If a protease is considered to participate in the pathology of AA amyloid, it must also demonstrate a spatial relationship to the substrate in situ. Using immunohistochemistry, we here found CathB and CathL in cells lining amyloid deposits and only CathB within amyloid deposits. CathB is relatively unstable at near neutral $\mathrm{pH}$ and loses its proteolytic activity with time, ${ }^{78}$ indicating that CathB probably has no significant extracellular proteolytic activity within the AA amyloid deposits. However, given the spatial and temporal co-localisation of enzymes and substrates, we deduce that CathB and CathL may still have a role in the pathology of AA amyloidosis.

AA amyloid proteins may be generated intracellularly, where they may be susceptible to proteolysis by CathB and CathL. ${ }^{5}$ In this case, the occurrence of AA amyloid proteins cannot be related to the product inhibition of lysosomal proteases: cleavage products obtained during proteolysis could inhibit a protease and, hypothetically, AA amyloid proteins generated during proteolysis may block enzymatic activity and prevent further degradation. However, both CathB and CathL completely degraded rSAA and native human AA amyloid proteins, making product inhibition by AA amyloid proteins highly unlikely. Among others factors, such as substrate concentration, and protease expression profile and $\mathrm{pH}$ stability, proteolysis of SAA and AA amyloid proteins may also depend on the interplay between proteases and glycosaminoglycans. Heparan sulphate (HS), a glycosaminoglycan, is a universal component of amyloid deposits. ${ }^{1}$ Interestingly, it was recently shown that the binding of membrane anchored HS to SAA, ${ }^{15}$ which changes the SAA tertiary structure towards a $\beta$ pleated sheet structure, ${ }^{1}$ is a critical step in amyloidogenesis. The conformational change of SAA induced by HS may decrease its proteolytic susceptibility. Interestingly, HS also binds CathB, resulting in decreased CathB exopeptidase activity, ${ }^{16}$ and thereby further inhibiting the complete proteolysis of SAA and AA amyloid proteins.

Future studies will have to show, which effect targeted deletion of these proteases has on SAA and AA amyloid protein catabolism and amyloid formation in vivo. 
Table 1 Currently identified proteolytic fragments and cleavages sites obtained by in vitro degradation of native* or recombinantt SAA are compared with AA amyloid proteins extracted from human tissue. Very few of the fragments generated thus far in vitro correspond with the 18 naturally occurring AA amyloid proteins identified until now

\begin{tabular}{|c|c|c|c|}
\hline Protease & Proteolytic fragments & $\begin{array}{l}\text { Fragments } \\
\text { corresponding to } \\
\text { naturally occurring } \\
\text { AA amyloid } \\
\text { proteins } \\
\text { No (\%) }\end{array}$ & Ref \\
\hline$M M P-1 * \neq$ & $\begin{array}{l}\mathrm{Arg}^{1} \text { to } \mathrm{Ala}^{57} \\
\mathrm{ll}^{58} \text { to } \mathrm{Tyr}^{104} \\
\mathrm{Leu}^{7} \text { to } \mathrm{Tyr}^{29} \text {, } \mathrm{Gly}^{8} \text { to } \\
\mathrm{ll}^{30} \text { or } \mathrm{Glu}^{9} \text { to } \mathrm{Gly}^{31}\end{array}$ & $0 / 18$ & 4 \\
\hline MMP-2* & $\begin{array}{l}\text { Arg }^{1} \text { to } \mathrm{Gly}^{51} \\
\text { Val }^{52} \text { to } \mathrm{Tyr}^{104} \\
\mathrm{Trp}^{8} \text { to } \mathrm{Ala}^{55}\end{array}$ & $0 / 18$ & 4 \\
\hline MMP-3* & $\begin{array}{l}\mathrm{Gly}^{8} \text { to } \mathrm{Ala}^{55} \\
\mathrm{Ser}^{2} \text { to } \mathrm{Ala}^{57} \\
\mathrm{Ser}^{2} \text { to } \mathrm{Glu}^{56} \\
\mathrm{Ser}^{2} \text { to } \mathrm{Gly}^{51} \\
\mathrm{Ala}^{57} \text { to } \mathrm{Tyr}^{104} \\
\mathrm{Ie}^{58} \text { to } \mathrm{Tyr}^{104} \\
\mathrm{Glu}^{74} \text { to } \mathrm{Tyr}^{104}\end{array}$ & $0 / 18$ & 4 \\
\hline CathB† & $\begin{array}{l}\mathrm{Ser}^{76} \text { to } \mathrm{Leu}^{77} \\
\mathrm{Asn}^{83} \text { to } \mathrm{Glu}^{84}\end{array}$ & $2 / 18(11)$ & 14 \\
\hline CathB† & (see figs 3 and 5) & $9 / 18(50)$ & $\begin{array}{l}\text { Present } \\
\text { study }\end{array}$ \\
\hline Cathl† & (see figs 3 and 5) & $0 / 18$ & $\begin{array}{l}\text { Present } \\
\text { study }\end{array}$ \\
\hline CathD† & $\begin{array}{l}\text { Cleavage sites } \\
\text { Phe }^{6}-\text { Leu }^{7} \\
\text { Glu }^{9}-\text { Ala }^{10} \\
\text { Asp }^{12}-\text { Gly }^{13} \\
\text { Arg }^{15}-\text { Asp }^{16} \\
\text { Ala }^{20}-\mathrm{Tyr}^{21} \\
\text { Ala }^{27}-\text { Asn }^{28} \\
\text { Asn }^{28}-\mathrm{Tyr}^{29}\end{array}$ & $0 / 18$ & 17 \\
\hline Elastase & $\begin{array}{l}\mathrm{Ala}^{27}-\mathrm{Asn}^{28} \\
\mathrm{ll}^{58}-\mathrm{Ser}^{59} \\
\mathrm{ll}^{65}-\mathrm{Gln}^{66}\end{array}$ & $1 / 18(6)$ & 14 \\
\hline
\end{tabular}

\section{ACKNOWLEDGEMENTS}

We thank Stacy Carl-McGrath, Sophie Mansfeld, and Yvonne Ducho for their excellent and skilful assistance.

This work was supported by grants from the Deutsche Forschungsgemeinschaft (grant No RO 1173/3-3), Bonn BadGodesberg, Germany and the Wilhelm Vaillant-Stiftung, Munich, Germany.

\section{Authors' affiliations}

C Röcken, S Vöckler, B Stix, S Krüger, A Roessner, Institute of Pathology, Otto-von-Guericke-University of Magdeburg, Germany R Menard, Biotechnology Research Institute, NRCC, Montreal, Canada
F Bühling, Institute of Immunology, Otto-von-Guericke-University of Magdeburg, Germany

J Raynes, Immunology Unit, Department of Infectious and Tropical Diseases, London School of Hygiene and Tropical Medicine, London, UK T Kähne, Institute of Experimental Internal Medicine, Otto-von-GuerickeUniversity of Magdeburg, Germany

\section{REFERENCES}

1 Röcken C, Shakespeare A. Pathology, diagnosis and pathogenesis of AA amyloidosis. Virchows Arch 2002;440:111-22.

2 Migita K, Eguchi K, Tsukada T, Kawabe Y, Takashima H, Mine M, et al. Increased circulating serum amyloid A protein derivatives in rheumatoid arthritis patients with secondary amyloidosis. Lab Invest 1996;75:371-5.

3 Migita K, Yamasaki S, Shibatomi K, Ida H, Kita M, Kawakami A, et al. Impaired degradation of serum amyloid A (SAA) protein by cytokinestimulated monocytes. Clin Exp Immunol 2001;123:408-11.

4 Stix B, Kähne T, Sletten K, Raynes J, Roessner A, Röcken C. Proteolysis of AA amyloid fibril proteins by matrix metalloproteinases-1, -2, and -3. Am J Pathol 2001;159:561-70.

5 Kluve-Beckerman B, Manaloor JJ, Liepnieks JJ. A pulse-chase study tracking the conversion of macrophage-endocytosed serum amyloid $A$ into extracellular amyloid. Arthritis Rheum 2002;46:1905-13.

6 Röcken C, Stix B, Brömme D, Ansorge S, Roessner A, Bühling F. A putative role for cathepsin $\mathrm{K}$ in degradation of $\mathrm{AA}$ and $\mathrm{AL}$ amyloidosis. Am J Pathol 2001;158:1029-38.

7 Barrett AJ, Rawlings ND, Woessner Jr JF. Handbook of proteolytic enzymes. San Diego, London, New York: Academic Press, 1998

8 Chapman HA, Riese RJ, Shi GP. Emerging roles for cysteine proteases in human biology. Annu Rev Physiol 1997;59:63-88.

9 Bühling F, Reisenauer A, Gerber A, Krüger S, Weber E, Brömme D, et al. Cathepsin $\mathrm{K}-$ a marker of macrophage differentiation? J Pathol 2001;195:375-82.

10 Müller D, Roessner A, Röcken C. Distribution pattern of matrix metalloproteinases (MMP-1, -2, -3, and -9), tissue inhibitors of matrix metalloproteinases (TIMP-1 and -2), and $\alpha 2$-macroglobulin in cases of generalized AA- and AL amyloidosis. Virchows Arch 2000;437:521-7.

11 Röcken C, Kientsch-Engel R, Mansfeld S, Stix B, Stubenrauch K, Weigle B, et al. Advanced glycation end products and receptor for advanced glycation end products in AA amyloidosis. Am J Pathol 2003;162:1213-20.

12 Chowdhury SF, Sivaraman J, Wang J, Devanathan G, Lachance P, Qi H, et al. Design of noncovalent inhibitors of human cathepsin L. From the 96residue proregion to optimized tripeptides. J Med Chem 2002;45:5321-9.

13 Bohne S, Sletten K, Menard R, Bühling F, Vockler S, Wrenger E, et al. Cleavage of $A L$ amyloid proteins and AL amyloid deposits by cathepsins $B, K$, and L. J Pathol 2004;203:528-37.

14 Yamada T, Liepnieks JJ, Kluve-Beckerman B, Benson MD. Cathepsin B generates the most common form of amyloid $A$ (76 residues) as a degradation product from serum amyloid A. Scand J Immunol 1995;41:94-7.

15 Elimova E, Kisilevsky R, Szarek WA, Ancsin JB. Amyloidogenesis recapitulated in cell culture: a peptide inhibitor provides direct evidence for the role of heparan sulfate and suggests a new treatment strategy. FASEB J. 2004;18: 1749-51, Epub 2 September, 2004.

16 Almeida PC, Nantes IL, Chagas JR, Rizzi CC, Faljoni-Alario A, Carmona E, et al. Cathepsin B activity regulation. Heparin-like glycosaminogylcans protect human cathepsin B from alkaline $\mathrm{pH}$-induced inactivation. J Biol Chem $2001 ; 276: 944-51$

17 Yamada T, Kluve-Beckerman B, Liepnieks JJ, Benson MD. In vitro degradation of serum amyloid $A$ by cathepsin $D$ and other acid proteases: possible protection against amyloid fibril formation. Scand J Immunol 1995:41:570-4.

18 Westermark GT, Sletten K, Westermark P. Massive vascular AA-amyloidosis: a histologically and biochemically distinctive subtype of reactive systemic amyloidosis. Scand J Immunol 1989;30:605-13.

19 Prelli F, Pras M, Shtrasburg S, Frangione B. Characterization of high molecular weight amyloid A proteins. Scand J Immunol 1991;33:783-6.

20 Baba S, Takahashi T, Kasama T, Shirasawa H. Identification of two novel amyloid A protein subsets coexisting in an individual patient of AAamyloidosis. Biochim Biophys Acta 1992;1180:195-200.

21 Erken E, Gray M, Cohen AS, Skinner M. Sequence analysis of amyloid protein AA from a Turkish patient with familial Mediterranean fever-documentation

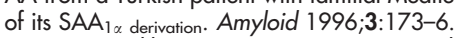

22 Levin $M$, Franklin EC, Frangione B, Pras $M$. The amino acid sequence of a major nonimmunoglobulin component of some amyloid fibrils. $J$ Clin Invest 1972;51:2773-6.

23 Westermark GT, Westermark P, Sletten K. Amyloid fibril protein AA. Characterization of uncommon subspecies from a patient with rheumatoid arthritis. Lab Invest 1987;57:57-64. 